\title{
Improvement in Descaling of Hot Strip by Hydrochloric Acid
}

\author{
Susumu YAMAGUCHI, Teruo YOSHIDA ${ }^{1)}$ and Takaho SAITO ${ }^{2)}$
}

Technical Development Bureau, Nippon Steel Corporation, Shintomi, Futtsu, Chiba-ken, 299-12 Japan.

1) Sheet \& Coil Division, Hirohata Works, Nippon Steel Corporation, Fujimachi, Hirohata-ku, Himeji, Hyogo-ken, 671-11 Japan. $\quad 2$ 2) Kazusa Office, Nippon Techno Research, Shintomi, Futtsu, Chiba-ken, 299-12 Japan.

(Received on March 14, 1994; accepted in final form on May 25, 1994)

\begin{abstract}
Mechànism of descaling process by hydrochloric acid was observed and a mathematical model was established, which indicated correct direction of improvement in pickling method, such as installing predescaler prior to acid tanks.

Various factors dominating descaling time were also investigated by experiments. By combining all the facts and theories obtained, a simulation program was developed which made possible the prediction of acid concentration distribution along the acid tanks. By utilizing the simulator optimization of pickling facilities specification became possible.
\end{abstract}

KEY WORDS: pickling; modeling; predescaler; mass transfer; descaling.

\section{Introduction}

In order to streamline a cold mill complex, integration of adjacent production lines has been carried out in various steel works. One of the most important problems in integration of the lines was to reduce the length of each production line. Especially a conventional pickling line by $\mathrm{HCl}$ was too long to unite a tandem cold rolling mill. In order to reduce the length of pickling line, a mathematical model by which direction of the improvement was indicated, was established at first. Then, the best method was selected by beaker test level. Various factors which dominated the descaling speed were also studied. Finally a simulation program was developed to optimize the design of actual descaling facilities.

\section{Modeling of Descaling Process by $\mathbf{H C l}$}

\subsection{Experiment to Observe Descaling Process}

The descaling process by $\mathrm{HCl}$ was observed in depth by using a test device shown in Fig. 1. The test pieces were immersed in $\mathrm{HCl}$ solution at constant speed. Then at certain point in time they were quickly drawn out of acid and washed immediately to freeze the situation. Test conditions are shown in Table 1. Material tested is tabulated in Table 2.

Photographic observation made clear following facts. Descaling process was basically separated in 2 stages. At the first stage, chemical cracks began to generate at favored spots and cracks penetrated to the boundary of the scale and the ferrite matrix increasing their number as time elapsed. The second stage started when number of cracks (density of cracks) became large enough. Then lateral solution of the scale began at the bound- ary between the scale and the ferrite. At this moment the separation of the scale as bulk started off as well. The descaling process of the scale with large content of $\mathrm{FeO}$ was a bit different from this. In the case of the scale rich in $\mathrm{FeO}$, the cracks did not penetrate directly to the ferrite, but made a detour by solving $\mathrm{FeO}$ selectively before reaching the bottom of the scale.

Result of the observation is schematically shown in Figs. 2 and 3. As generally believed, $\mathrm{FeO}$ is easy to solve by $\mathrm{HCl}$ compared with $\mathrm{Fe}_{3} \mathrm{O}_{4}$ or $\mathrm{Fe}_{2} \mathrm{O}_{3}$. ${ }^{1)}$ Scale with rich $\mathrm{FeO}$, therefore, was said to be solved in short time as a whole. ${ }^{2,3)}$ And it was also said that in the

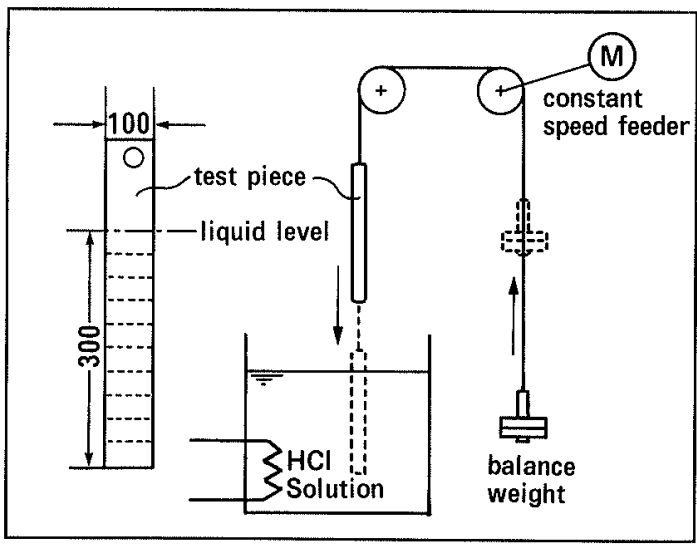

Fig. 1. Testing device.

Table 1. Test condition.

$\begin{array}{lrcc}\mathrm{HCl} \text { concentration }(\%) & 5 & 8 & \\ \mathrm{FeCl}_{2} \text { concentration }(\mathrm{g} / \mathrm{l}) & 200 & & \\ \text { Solution temperature }\left({ }^{\circ} \mathrm{C}\right) & 50 & 70 & \\ \text { Immersion speed }(\mathrm{mm} / \mathrm{sec}) & 5 & 10 & 15\end{array}$


Table 2. Test piece condition.

\begin{tabular}{|c|c|c|c|c|c|}
\hline \multirow{2}{*}{$\begin{array}{l}\text { Test } \\
\text { piece }\end{array}$} & \multirow{2}{*}{$\begin{array}{c}\text { Cooling } \\
\text { temperature } \\
\left({ }^{\circ} \mathrm{C}\right)\end{array}$} & \multirow{2}{*}{$\begin{array}{c}\text { Scale } \\
\text { amount } \\
\left(\mathrm{g} / \mathrm{m}^{2}\right)\end{array}$} & \multicolumn{3}{|c|}{ Scale composition } \\
\hline & & & $\mathrm{FeO}$ & $\begin{array}{c}\mathrm{Fe}_{3} \mathrm{O}_{4} \\
(\%)\end{array}$ & $\mathrm{Fe}_{2} \mathrm{O}_{3}$ \\
\hline A & 560 & 54 & 0 & 100 & 0 \\
\hline B & 620 & 39 & 2 & 98 & 0 \\
\hline $\mathrm{C}$ & 740 & 64 & 73 & 27 & 0 \\
\hline $\mathrm{D}$ & 700 & 49 & 0 & 100 & 0 \\
\hline
\end{tabular}

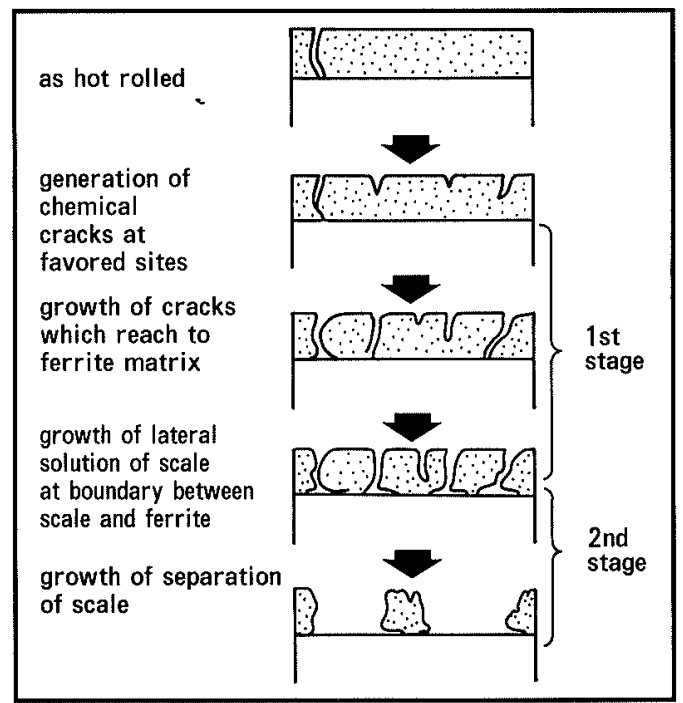

Fig. 2. Schematic diagram of descaling process by $\mathrm{HCl}$ (For scale free of $\mathrm{FeO}$ ).

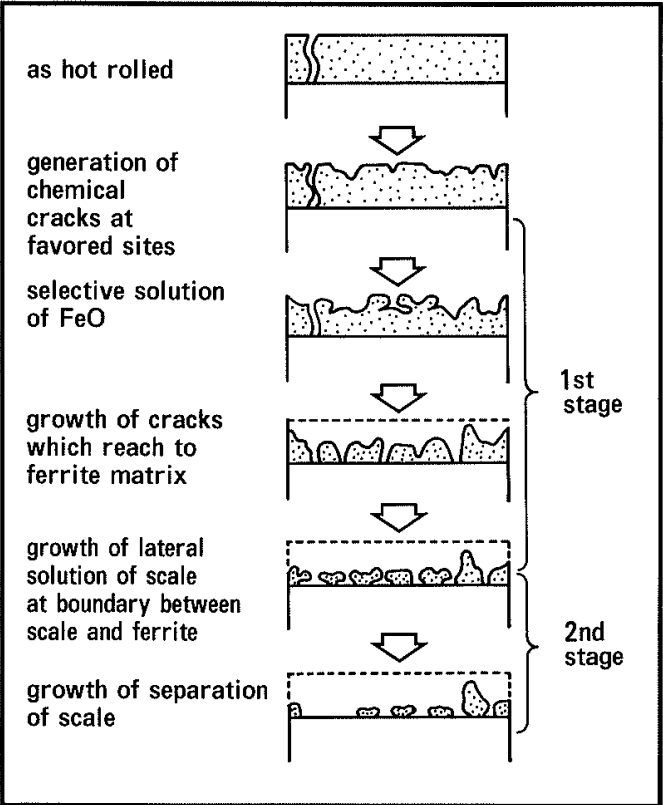

Fig. 3. Schematic diagram of descaling process by $\mathrm{HCl}$ (For scale with $73 \% \mathrm{FeO}$ ).

case of pickling by $\mathrm{HCl}$, the scale solved from the surface to the bottom layer by layer. ${ }^{3)}$ But the photographic observation contradicted these theories.

In order to make quantitative statement, amount of residual scale, number of cracks developed, scale coverage were measured in the course of descaling using

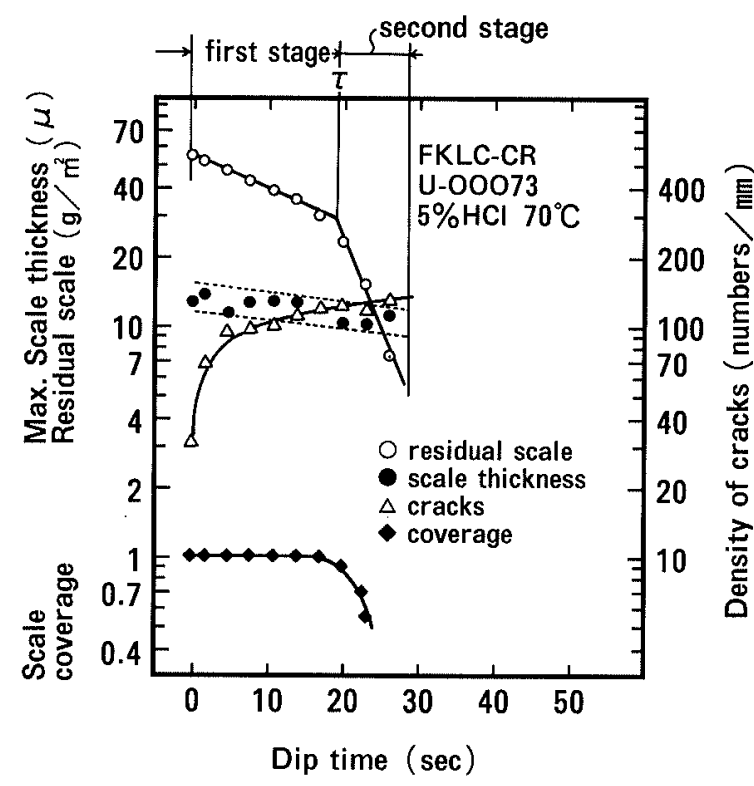

Fig. 4. Descaling process by $\mathrm{HCl}$ (For scale free of $\mathrm{FeO}$ ).

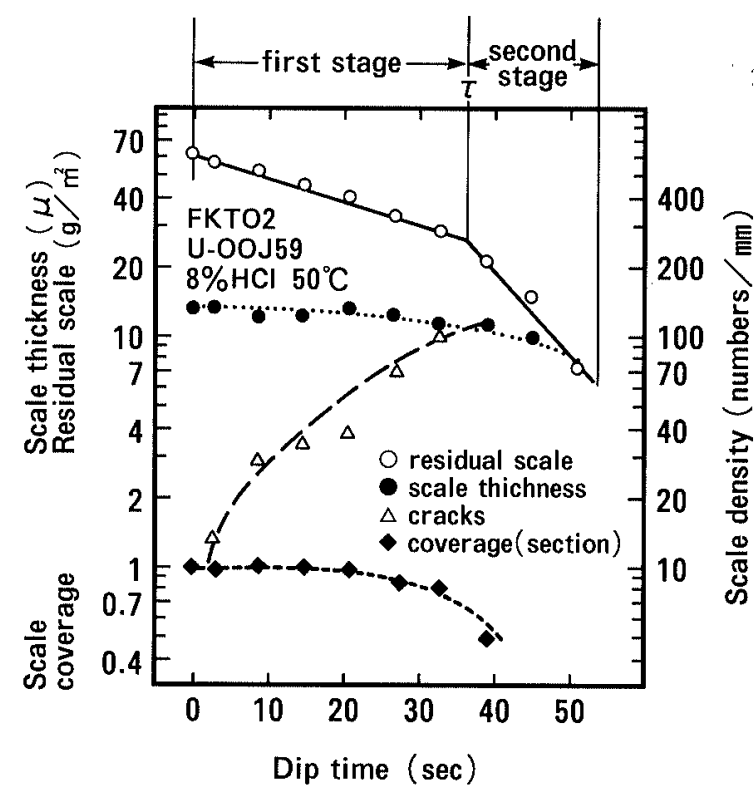

Fig. 5. Descaling process by $\mathrm{HCl}$ (For scale with $73 \% \mathrm{FeO}$ ).

the same test method mentioned above. The test result is shown in Figs. 4 and 5.

Figure 4 shows the result about the scale without $\mathrm{FeO}$. Figure 5 shows the result about $\mathrm{FeO}$ rich scale. From these figures it is obvious that in the case of the scale without $\mathrm{FeO}$, at early stage of descaling, number of cracks increases sharply, and at time $\tau$ it begins to saturate. On the other hand residual scale is represented by 2 lines with different inclination if logarithmic scale is adopted for vertical axis. The meeting point of 2 lines is the transition point from the first stage to the second stage that corresponds to the saturation point of density of cracks. The scale coverage is almost constant during the first stage, but begins to reduce at a transition point. That means separation of the scale is a dominant factor in descaling process at the second stage. In the case of $\mathrm{FeO}$ rich scale, transition time is delayed by selective solution of $\mathrm{FeO}$ during the first stage. But basic 
mechanism of descaling for both types of scale is fundamentally equivalent.

\subsection{Modeling of Descaling Process by $\mathbf{H C l}$}

Based on the facts obtained in previous section modeling of descaling processes by $\mathrm{HCl}$ was tried.

At the first stage;

It is supposed that amount of solved scale is proportional to time elapsed and coverage by scale $W_{1}$. Then a following equation is obtained.

$$
-d W=k_{1}\left(W_{1} / W\right) d t
$$

Integrating Eq. (1), following result is got.

$$
\begin{gathered}
\left(W_{0}+W\right)+(1-\alpha) W_{0} \exp \left\{\frac{W-(1-\alpha) W_{0}}{\alpha W_{0}}\right\} \\
=-k_{1}\left\{\left(n_{0}+n_{f}\right) t+n_{f}\left(e^{-\beta t}-1\right) / \beta\right\} \ldots .
\end{gathered}
$$

At the second stage;

Basic equation at the second stage is,

$$
-d W=k_{2} n\left(W / W_{\tau}\right) d t
$$

Integrating Eq. (3), following result is got.

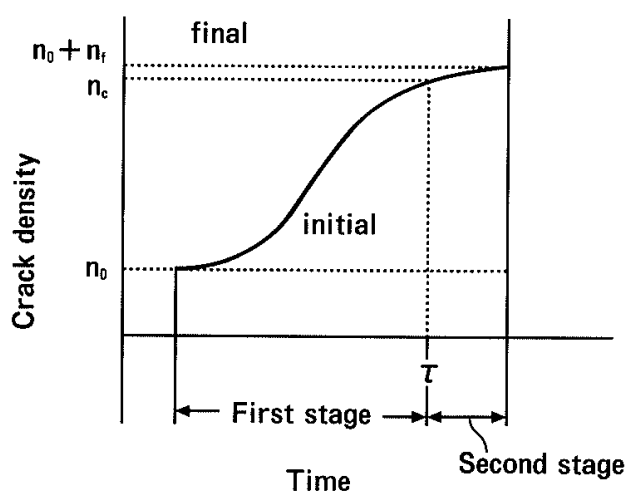

Fig. 6. Growth of crack density in time.

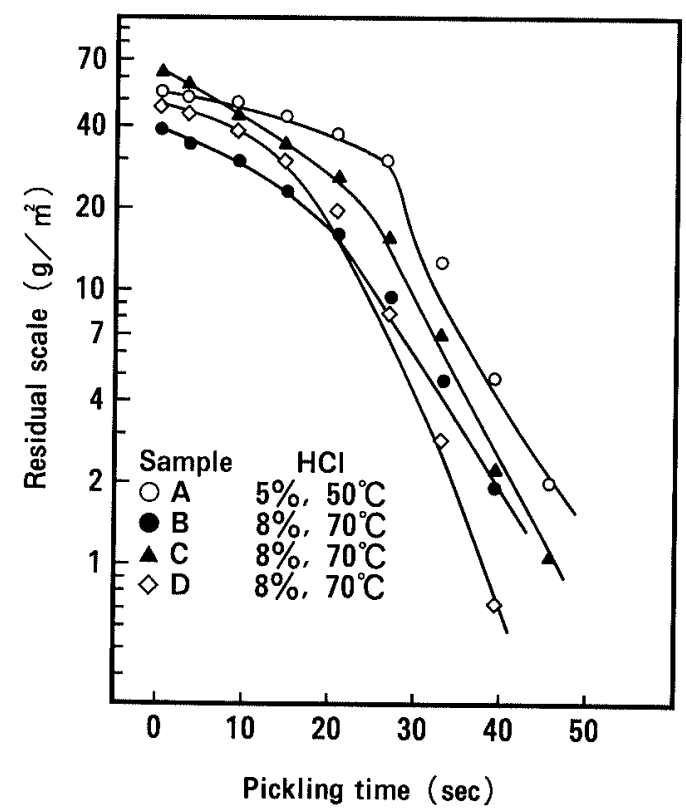

Fig. 7. Comparison of calculated and experimental value.

$$
\begin{aligned}
& \exp \left(W / W_{\tau}\right) \\
& =-\left(k_{2} / W_{\tau}\right)\left\{\left(n_{0}+n_{f}\right)(t-\tau)+\left(n_{f} / \beta\right)\left(e^{-\beta t}-e^{-\beta \tau}\right)\right\}
\end{aligned}
$$

In these calculation it is supposed that cracks grow exponentially as shown in Fig. 6.

The curve shown in Fig. 6 is represented by the following equation.

$$
n=n_{0}+n_{f}\left(1-e^{-\beta t}\right)
$$

By utilizing multi variable successive approximation non-determined coefficients were fixed.

The result is shown in Fig. 7 which demonstrates reasonable coincidence between observed value and calculated value. That is, modeling is correct.

\subsection{Direction of Improvement in Descaling by $\mathbf{H C l}$}

From the model obtained in the previous section following trials must be effective.

1) To give artificial cracks prior to descaling by a predescaler. (To increase $n_{0}$ )

2) To decrease the amount of the scale. (To reduce $\left.W_{0}\right)$

3) To change scale composition.

4) To increase the supply of $\mathrm{H}^{+}$to scale surface. (Items 3) and 4) must increase $k_{1}, k_{2}$ and $\beta$.)

In order to confirm these expected effects various experiments were carried out as follows.

\section{Effect of Predescaler}

To give artificial cracks to the scale before pickling. 3 types of predescalers were selected, namely, a tension leveller (T/L), Skin Pass Mill (SPM) and PV mill (PV). ${ }^{4)}$

\subsection{Result of Laboratory Test}

Figure 8 shows how the descaling time decreases when the strip is elongated prior to pickling. Test samples were taken from strip center and edge of the middle of hot coils longitudinally. Figure 8 only shows the result for samples from strip center.

In Fig. 8 horizontal axis represents the strip elonga-

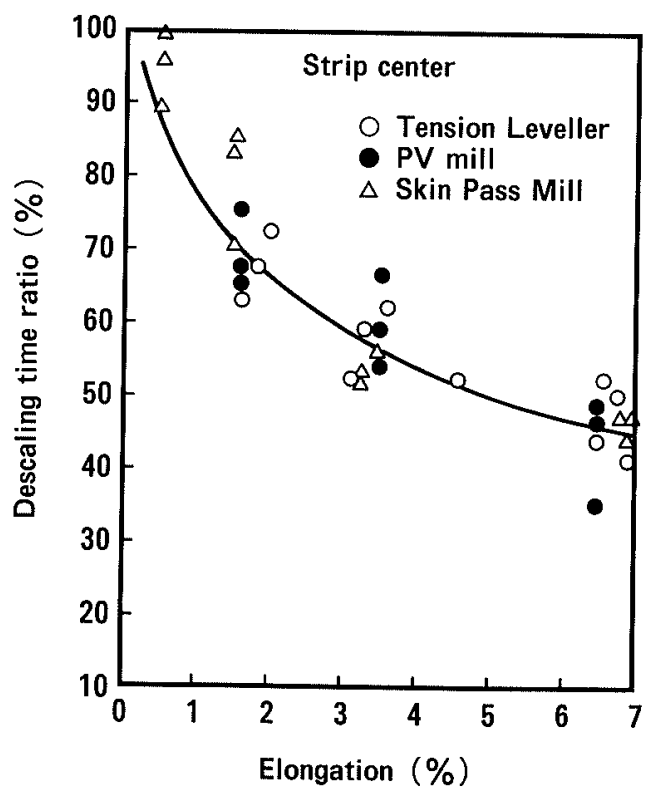

Fig. 8. Elongation of strip and descaling time ratio. 


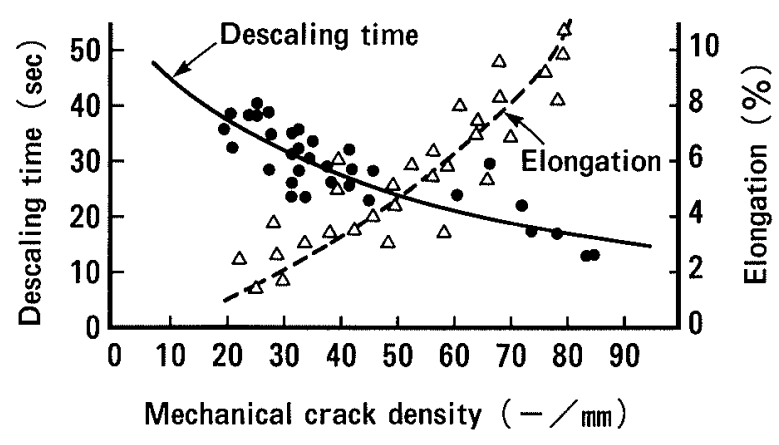

Fig. 9. Mechanical crack density and descaling time.

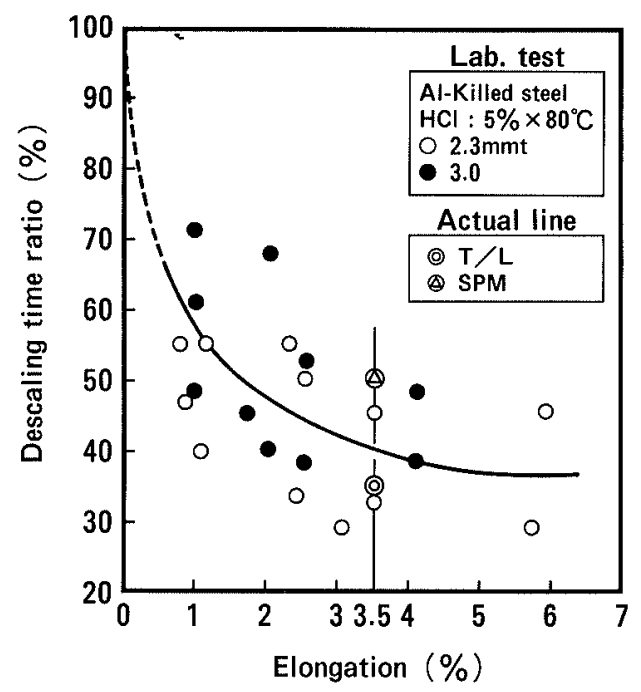

Fig. 10. Elongation and descaling time ratio (Comparison with lab. test and actual production).

tion given by predescalers and vertical axis represents ratio of descaling time required against the case in which the elongation is zero. It is evident from this figure that descaling time reduces as the elongation increases. It is also obvious that the type of descalers is irrelevant. But from the economical point of view, the $\mathrm{T} / \mathrm{L}$ was found out to be the best choice.

Figure 9 shows the relationship between crack density given by $\mathrm{T} / \mathrm{L}$ and descaling time. It shows crack density contributes to the decrease in descaling time. It also proves that crack density is increased by elongation.

\subsection{Confirmation of the Laboratory Test Result by Actual Production Line}

Hot coils which were elongated $3.5 \%$ by $\mathrm{T} / \mathrm{L}$ and $\mathrm{SPM}$ were descaled in actual production line to confirm if the same results as laboratory test would be obtained.

Figure 10 shows that the descaling time ratio is almost same for both cases. But in terms of absolute value, descaling time required in actual production line was smaller than that of laboratory test by about $20 \%$. This fact suggests that strip speed has some effect on decrease in descaling time. This matter will be discussed in detail in Chap. 6.

The curve shown in Fig. 10 was obtained by adopting worse data comparing data for edge and center of the strip for practical reason.

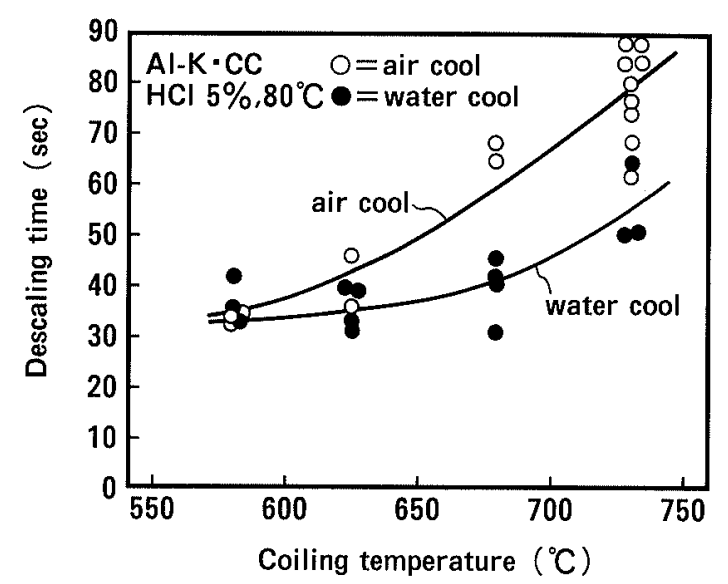

Fig. 11. Relationship between coiling temperature and descaling time.

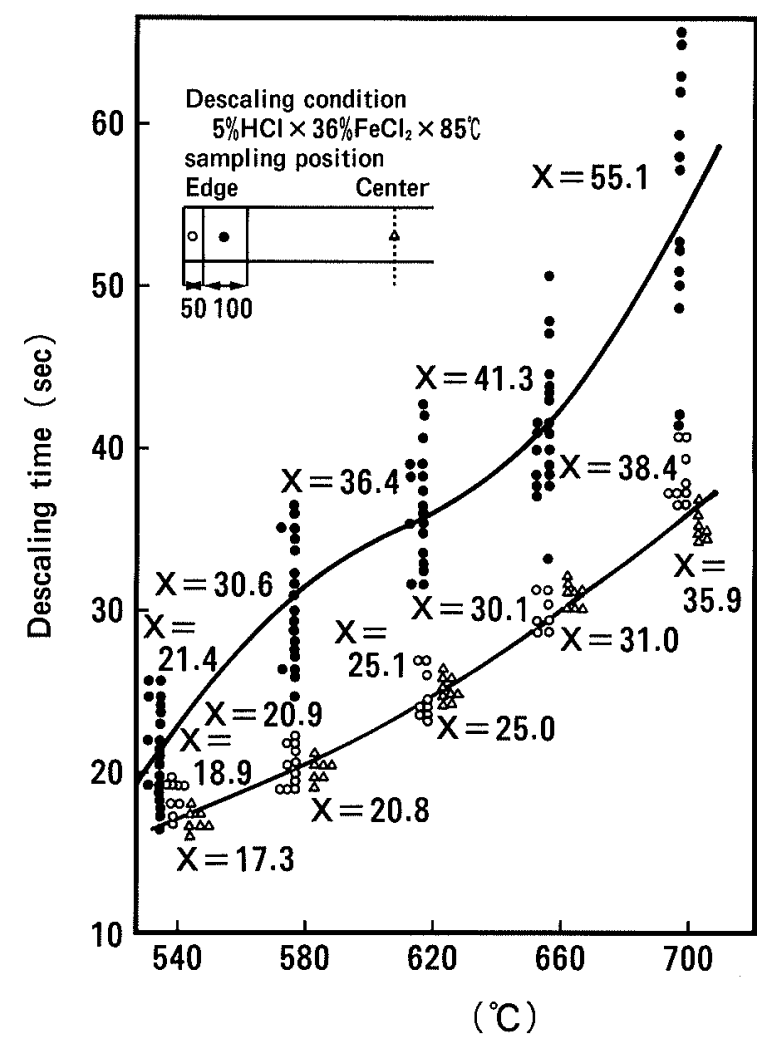

Fig. 12. Relationship between coiling temperature and descaling time for different position along strip width.

\section{Decreasing Scale Amount}

It is well known from the operational experience that coiling temperature and cooling method of hot coils affect the descaling time greatly. So effects of these factors were investigated quantitatively.

\subsection{Coiling Temperature and Descaling Time}

Figure 11 shows relationship between coiling temperature and descaling time for different cooling method of hot coils. The figure clearly indicates that descaling time increases as the coiling temperature rises, both for air cooled and water cooled hot coils. It also shows that water cooled coil requires less time for descaling. These 2 curves were obtained by pickling the samples gathered from strip edge. In order to study more in detail, de- 
scaling time was measured separately about samples from edge and center. The test result is shown in Fig. 12. Figure 12 shows that the scale of strip center and extreme edge has almost the same nature as long as descaling time is concerned. But the scale a bit inside of the edge (100 mm apart from edge) is most difficult to solve. This phenomenon is explained as follows. In the form of coil, hot strip edge is cooled most rapidly and the scale growth is suppressed. The growth of the scale is also suppressed at the coil center because $\mathrm{O}_{2}$ supply is not enough.

\subsection{Coiling Temperature and Scale Amount}

Relationship between coiling temperature and scale amount was investigated to analize why the descaling time required becomes longer as coiling temperature rises. Figure 13 shows the result. From Fig. 13 it is clear that the amount of the scale increases as the coiling temperature rises, especially in the case of air cooled hot coils. This tendency is not so sharp for water cooled hot coils. These 2 curves shown in Fig. 13 clearly explain why the coiling temperature affects the descaling time. They also explain why the water cooled hot coils require less time to be descaled. But it should be proved by experiments. Figure 14 shows the result of experiments carried out to find the relationship between scale amount and the descaling time. It is evident from Fig. 14 that the descaling time and the amount of scale is in linear relationship at certain range of scale amount. A conclusion obtained from the argument developed in this section is that lowering coiling temperature and

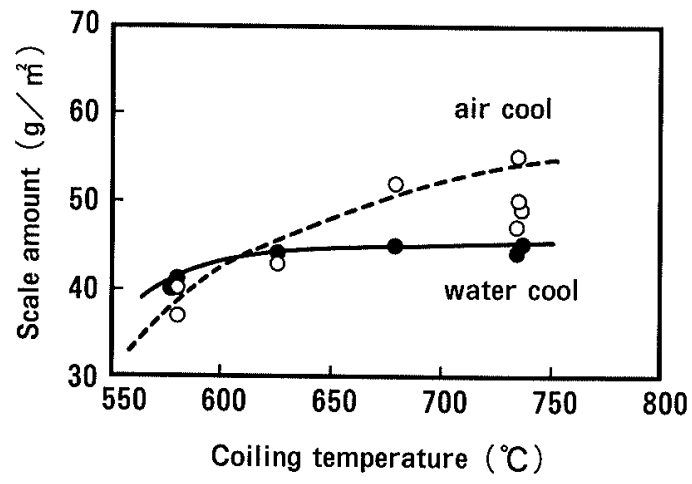

Fig. 13. Coiling temperature and scale amount.

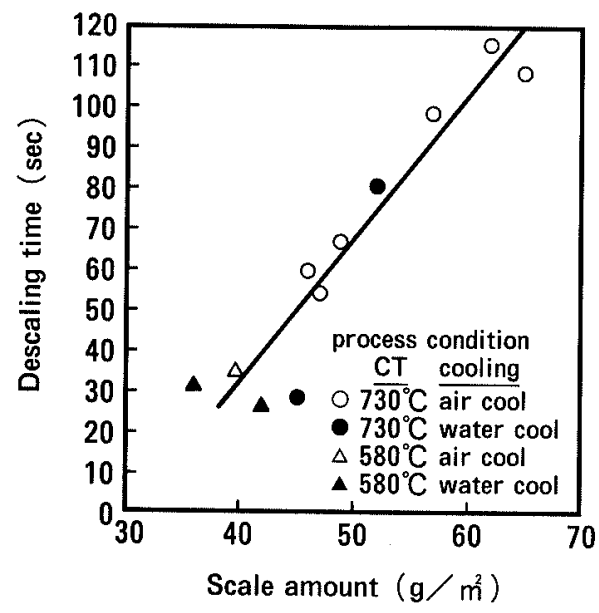

Fig. 14. Scale amount and descaling time. water cool of hot coils are both effective to reduce the descaling time. The coiling temperature, however, is determined metallurgically. Only the measure a designer of descaling facilities can take, therefore, is to install a rapid cooling device for hot coils.

\section{Changing of Scale Composition}

It is generally said that rapid cooling of hot coils changes the scale composition because transformation of $\mathrm{FeO}$ between $570-470^{\circ} \mathrm{C}$ is suppressed. ${ }^{1)}$ Figure 15 shows how the scale composition changes by cooling method and coiling temperature. It indicates that in the case of air cool, FeO content in the scale decreases as the coiling temperature rises. But in the case of water cool, FeO content sharply increases as the coiling temperature rises.

The experimental fact observed as above coincides with general belief. But as discussed in Chap. 2, the scale with high content of $\mathrm{FeO}$ requires longer time than the scale free of $\mathrm{FeO}$. So, reduction in descaling time by rapid cooling of hot coils is mainly caused by reduction in scale thickness.

\section{Increasing Supply of $\mathrm{H}^{-}$to Scale Surface}

To confirm the effect of sufficient supply of $\mathrm{H}^{+}$, spray pickling and jet flow pickling were experimented in laboratory and pilot line scale.

\subsection{Spray Pickling}

One of the results obtained by spray pickling in a pilot line is shown in Fig. 16 which indicates that the spray pickling can reduce descaling time by $55 \%$ for coil edge and center when $3.5 \%$ elongation is given prior to pickling.

Meaning of $\operatorname{Dip}(\mathrm{Lab}) \times$.0.8 written in the center column of Fig. 16 is as follows.

In Chap. 3 it was mentioned that in actual production line descaling time is about $80 \%$ of beaker test value. It was thought reasonable, therefore, to multiply lab. test value by 0.8 in comparing spray and actual dip pickling.

\subsection{JET Flow Pickling}

Configuration of the jet flow pickling is shown in Fig. 17. Strip runs through narrow duct in which counter flow of acid solution is provided by a pump. Result of jet flow pickling experiment is shown in Fig. 18 which tells

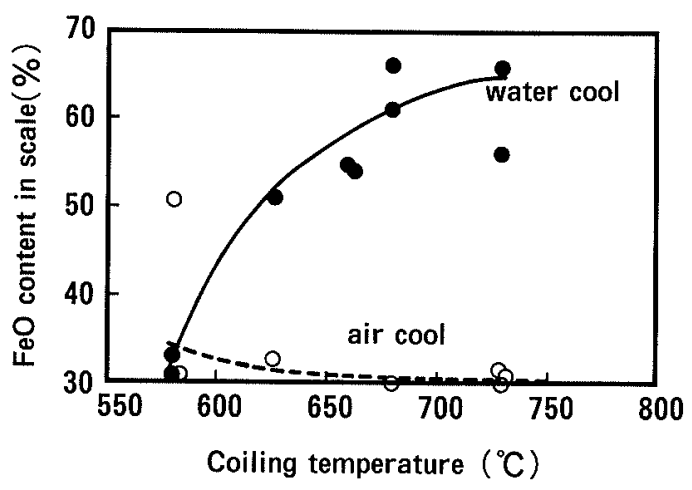

Fig. 15. FeO content in scale by different cooling condition. 


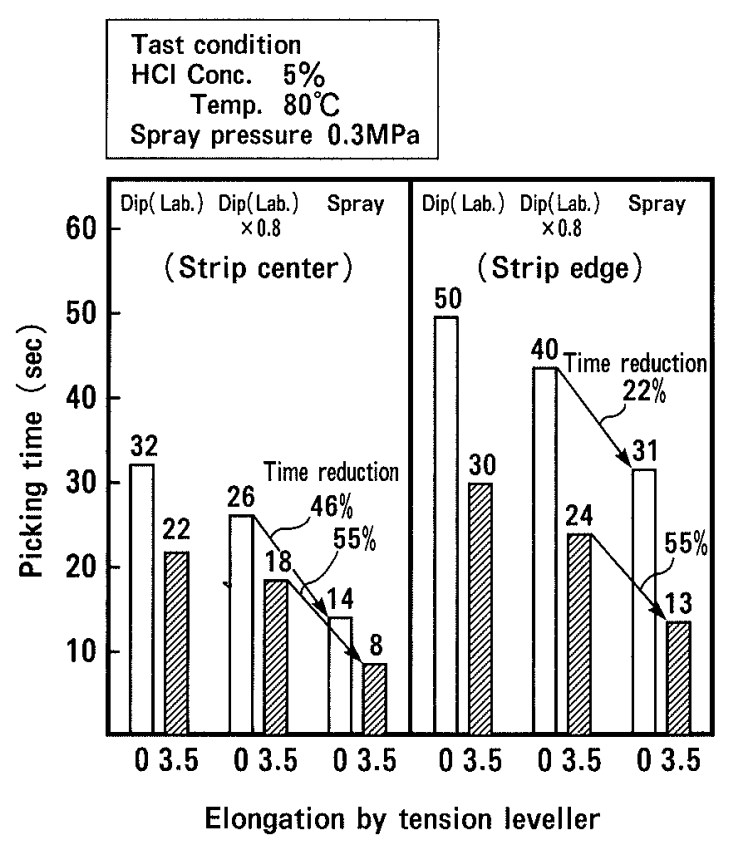

Fig. 16. Effect of spray pickling.

《/Flow of acid》

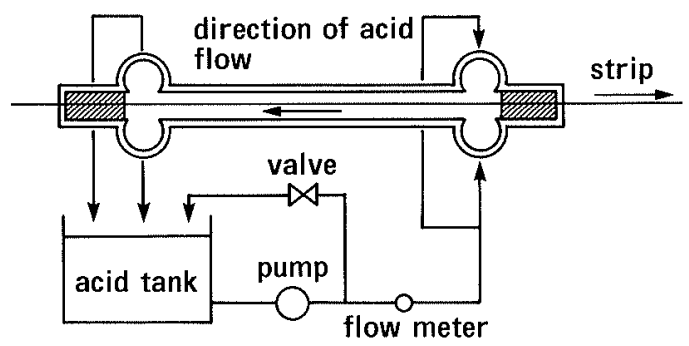

Fig. 17. Testing device of jet flow pickling.

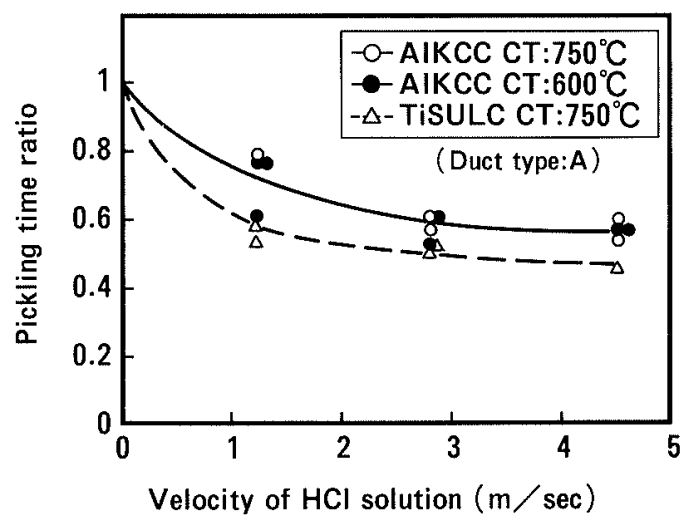

Fig. 18. Effect of velocity of $\mathrm{HCl}$ solution in jet flow pickling.

that as velocity of acid increases the pickling time ratio decreases. Pickling time ratio is defined as pickling time observed/pickling time at acid velocity zero. It was also found out that pickling time became even shorter if $3.5 \%$ of elongation was given prior to jet flow pickling by $30 \%$. Figure 18 also suggests that strip speed in conventional dip pickling should have the same effect. Because important factor is relative movement between strip and descaling media.

\subsection{Effect of Strip Speed in Dip Pickling}

Before investigating the effect of the strip speed in

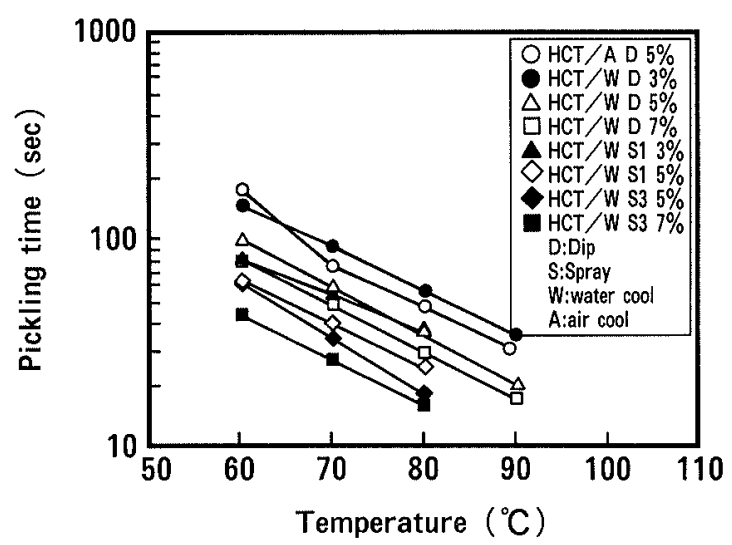

Fig. 19. Effect of acid temperature on pickling time.

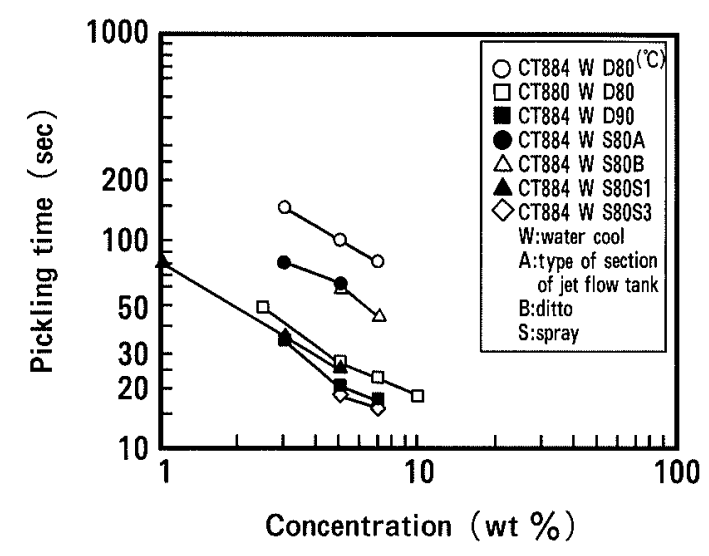

Fig. 20. Effect of acid concentration on pickling time.

actual pickling line, effect of temperature and concentration of $\mathrm{HCl}$ has to be made clear because in actual production line temperature and concentration of $\mathrm{HCl}$ are different from tank to tank. To compare the data obtained from actual production line with beaker test value, equalization of descaling capability of actual production line is necessary.

\subsubsection{Effect of Temperature and Concentration of $\mathrm{HCl}$ on Descaling Capability}

Figure 19 shows the effect of the acid temperature. Eight curves for material treated in different condition are drawn in Fig. 19. Effect of the acid concentration on descaling time for material treated by 7 different conditions is shown in Fig. 20. Figures 19 and 20 brings about the experimental equation as follows.

$$
T_{0}=a\left\{\exp (-\theta \ln 5 / 30) D^{-\log 6}\right\}
$$

where, $T_{0}$ : Pickling time

$\theta:$ Acid temperature $\left({ }^{\circ} \mathrm{C}\right)$

$D:$ Acid concentration (\%)

$a$ : Constant.

$T_{0}$ does not represent absolute value.

6.3.2. Descaling Capability of Actual Production Line

By utilizing Eq. (6), the descaling capability of the actual production line was evaluated supposing as if the actual line was a big beaker.

Table 3 shows the evaluation result of Nos. 1 and 4 pickling line in Yawata Works of Nippon Steel Corp. The value of the descaling capability ratio written in the 
5th column of Table 3, was obtained as follows. Firstly the descaling time $T_{0}$ by $5 \%$ conc. and $80^{\circ} \mathrm{C} \mathrm{HCl} \mathrm{solution}$ was calculated. Then, descaling time coresponding each tank of actual line was calculated. The ratio of descaling time in $\mathrm{HCl}$ solution of $5 \%$ and $80^{\circ} \mathrm{C}$ to descaling time of each actual acid tank in production line is called descaling capability ratio. After preparing these data several hot coils were actualy processed through Nos. 1 and 4 pickling lines and marginal strip speed to remove the scale competely. Before testing in actual production line test pieces were taken from the same hot coils. The test pieces were immersed in a beaker filled with $5 \%$ conc. and $80^{\circ} \mathrm{C} \mathrm{HCl}$ solution to know basic descaling time of the hot coils to be tested. Test result is tabulated in Table 4. Expected descaling time in production line written in 9th column was obtained by multiplying descaling time observed by beaker test (8th column of Table 4) by descaling capability ratio defined in Sec. 6.3.2.

Actually, however, descaling time observed in actual production lines were shorter than the expected value. This phenomenon should be explained as strip speed effect. Therefore, discaling time ratio writtten in extreme right column of Table 4 which is obtained by dividing actual descaling time in production line by the expected descaling time represents strip speed effect on descaling time. The descaling time ratio against speeds are shown in Fig. 21.

\subsection{Evaluation of Pickling Method by Heat Transfer Coefficient}

The effect of the relative velocity between acid flow and the strip, desirably, has to be studied in theoretically.

Table 3. Acid tank condition of Nos. 1 and 4 pickling line.

\begin{tabular}{ccccc}
\hline $\begin{array}{c}\text { Pickling } \\
\text { line }\end{array}$ & $\begin{array}{c}\text { Tank } \\
\text { No. }\end{array}$ & $\begin{array}{c}\mathrm{HCl} \\
\text { conc. } \\
(\%)\end{array}$ & $\begin{array}{c}\text { Solution } \\
\text { temp. } \\
\left({ }^{\circ} \mathrm{C}\right)\end{array}$ & $\begin{array}{c}\text { Descaling } \\
\text { capability } \\
\text { ratio }\end{array}$ \\
\hline \multirow{2}{*}{1} & 1 & 3.0 & 68 & 0.353 \\
& 2 & 3.9 & 68 & 0.433 \\
& 3 & 6.9 & 68 & 0.675 \\
& 4 & 6.5 & 68 & 0.645 \\
\hline 4 & & & & Average 0.527 \\
& 1 & 2.0 & 87 & 0.713 \\
& 2 & 3.0 & 82 & 0.748 \\
& 3 & 5.0 & 82 & 1.113 \\
& 4 & 5.0 & 82 & 1.113 \\
& & & \multicolumn{3}{c}{ Average 0.922} \\
& & & &
\end{tabular}

Relevant field of theory that treats this problem must be boundary theory of mass transfer. Probably resistance by mass transfer and chemical reaction at the surface of the scale are both dominant factors in industrial descaling processes. The proposed mechanism is illustrated schematically in Fig. 22.

However, it is very difficult to solve the problem by mass transfer in fluid flow, because physical property of $\mathrm{HCl}$ solusion concerning mass transfer such as diffusion coefficient is not available. To avoid this difficulty, heat transfer coefficient was introduced to evaluate the descaling method because there is analogy between mass transfer and heat transfer in fluid flow.

From this point of view, heat transfer coefficient was calculated both for various speed of flow in jet flow pickling and different speed of strip in conventional pickling.

Equations used for both processes are:

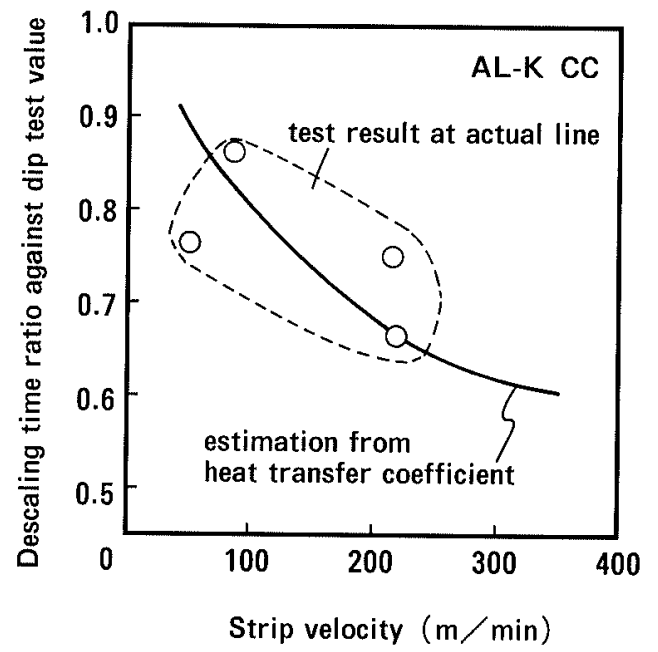

Fig. 21. Effect of strip velocity in dip tanks on descaling time.

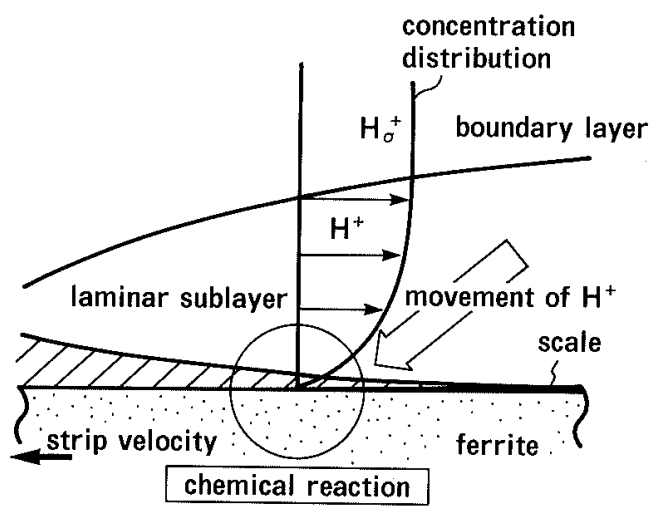

Fig. 22. Mechanism of pickling by $\mathrm{HCl}$ when strip is running.

Table 4. Strip speed effect on descaling time.

\begin{tabular}{|c|c|c|c|c|c|c|c|c|c|}
\hline $\begin{array}{l}\text { Test } \\
\text { coil }\end{array}$ & $\begin{array}{l}\text { Coiling } \\
\text { temp. } \\
\left({ }^{\circ} \mathrm{C}\right)\end{array}$ & $\begin{array}{l}\text { Coil } \\
\text { cooling } \\
\text { method }\end{array}$ & $\begin{array}{l}\text { Pickling } \\
\text { line } \\
\text { used }\end{array}$ & $\begin{array}{l}\text { Elongation } \\
\text { by } \mathrm{T} / \mathrm{L} \\
(\%)\end{array}$ & $\begin{array}{c}\text { Strip } \\
\text { speed } \\
(\mathrm{m} / \mathrm{min})\end{array}$ & $\begin{array}{l}\text { Actual descaling time } \\
\text { in production line } \\
(\mathrm{sec})\end{array}$ & $\begin{array}{c}\text { Descaling time } \\
\text { in beaker test } \\
(\mathrm{sec})\end{array}$ & $\begin{array}{l}\text { Expected time in } \\
\text { production line } \\
(\mathrm{sec})\end{array}$ & $\begin{array}{c}\text { Descaling } \\
\text { time ratio } \\
(\%)\end{array}$ \\
\hline 1 & 680 & Air & No. 1 & 0 & 50 & 96 & 67 & 127 & 76 \\
\hline 2 & 680 & Water & No. 1 & 0 & 80 & 60 & 37 & 70 & 86 \\
\hline 3 & 680 & Water & No. 1 & 0 & 220 & 22 & 28 & 30 & 73 \\
\hline 4 & 730 & Air & No. 4 & 0 & 220 & 22 & 30 & 33 & 66 \\
\hline
\end{tabular}




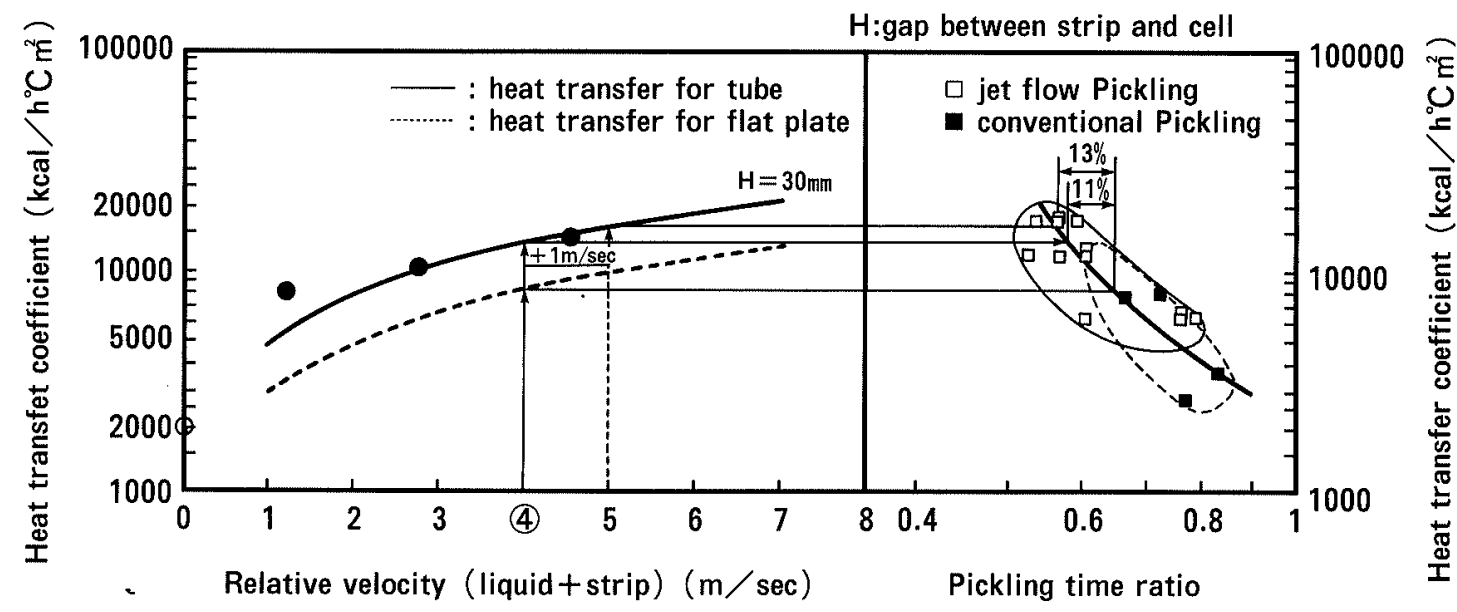

Fig. 23. Heat transfer coefficient and pickling time.

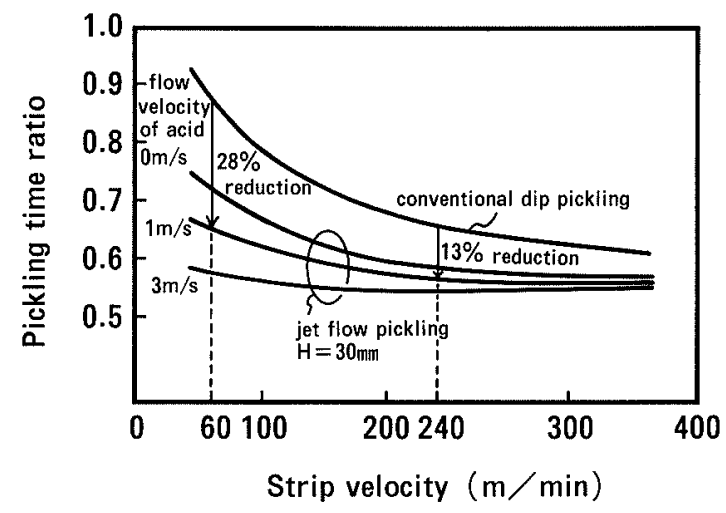

Fig. 24. Strip velocity and pickling time ratio.

For jet flow pickling: $\quad N u=0.23 \operatorname{Re}^{0.8} \operatorname{Pr}^{1 / 3}$

For dip pickling $\quad: \quad N u=0.0296 \operatorname{Re}^{0.8} \operatorname{Pr}^{1 / 3}$

Result of the study is shown in Fig. 23.

Left hand side of Fig. 23 shows the heat transfer coefficient calculated for jet flow and conventional pickling. Black points are measured value in jet flow test line. In right hand side of Fig. 23 marks are plotted against pickling time ratio at vertical positions that correspond to the relative speed shown in left hand side of Fig. 23.

The graph in the right hand side of Fig. 23 can be drawn because the relationship between relative speed and pickling time ratio has been already known in Secs. 6.2 and 6.3 .

Figure 23 shows that pickling time decreases as heat transfer coefficient increases. For instance, if the heat transfer coefficient is doubled, pickling time is decreased about $25 \%$. Figure 24 can be obtained from Fig. 23. Figure 24 clearly shows how pickling time changes as strip speed changes either in jet flow or in conventional pickling process. For example, at strip speed of $60 \mathrm{~m} / \mathrm{min}$ jet flow pickling with flow speed of $1 \mathrm{~m} / \mathrm{sec}$ requires less pickling time by $28 \%$ in comparison with conventional pickling. But at the point where strip speed is 240 $\mathrm{m} / \mathrm{min}$, jet flow pickling has only $13 \%$ reduction in pickling time. It is very important that evaluation of pickling facility can be made by comparing heat transfer coefficient. Because it eliminates the necessity of big scale

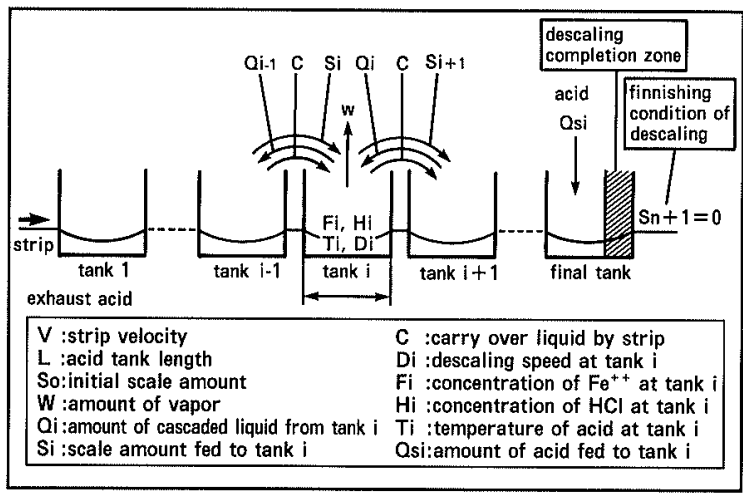

Fig. 25. Concept of acid concentration prediction model.

experiment.

\section{Evaluation of 3 Types of Pickling Process}

From various experimental and theoretical knowledge obtained so far, it is evident that following processes are almost equivalent as long as descaling time is concerned. Each of them can reduce the length of pickling section by half because descaling time becomes half in comparison with conventional pickling.

1) $\mathrm{T} / \mathrm{L}$ (3.5\% elongation) + Conventional pickling

2) $\mathrm{T} / \mathrm{L}(3.5 \%$ elongation $)+$ Spray pickling

3) $\mathrm{T} / \mathrm{L}$ (3.5\% elongation) + Jet flow pickling

By evaluating these processes economically, it was found that the combination of tension leveller and conventional dip pickling is the best choice when the production capacity is large.

\section{Simulation of Acid Concentration Distribution along Acid Tanks of Production Line}

In order to design an optimum pickling process, new design criteria should be established for dip pickling with $\mathrm{T} / \mathrm{L}$. A simulation program which can predict acid concentration distribution along acid tanks at design stage should be developed by utilizing all the facts and theories obtained so far. Then, optimum design of new pickling line would be possible. Concept of the simulation is shown in Fig. 25.

Basic method of constructing the simulation program 
Table 5. Prerequisite of simulation.

\begin{tabular}{|c|c|c|}
\hline No. & Prerequisite & Foundation \\
\hline 1 & $\begin{array}{l}\text { Descaling time is in linear relationship with scale } \\
\text { amount. }\end{array}$ & Fig. 14 \\
\hline 2 & Descaling time is dependent on $\mathrm{HCl}$ temperature. & Fig. 19 \\
\hline 3 & $\begin{array}{l}\text { Descaling time is dependent on } \mathrm{HCl} \text { concentra- } \\
\text { tion. }\end{array}$ & Fig. 20 \\
\hline 4 & Descaling process proceeds in 2 steps. & Figs. 4, 5 \\
\hline 5 & $\begin{array}{l}\text { Predescaling is effective on decrease in descaling } \\
\text { time. }\end{array}$ & Figs. 8,10 \\
\hline 6 & $\begin{array}{l}\text { Descaling time depnds on coiling temperature. } \\
\text { But the effect should be count separately for } \\
\text { edge and center of the strip. }\end{array}$ & Fig. 12 \\
\hline 7 & $\begin{array}{l}\text { Water vapor generated at acid tanks can be } \\
\text { evaluated by amount of exhaust fume which } \\
\text { should be saturated in air. }\end{array}$ & Hypothesis \\
\hline 8 & $\begin{array}{l}\text { Water cooling of hot coil is effective on decrease } \\
\text { in descaling time. }\end{array}$ & Fig. 11 \\
\hline 9 & $\begin{array}{l}\text { Acid amount carried over by strip is propor- } \\
\text { tional to square of the strip speed. }\end{array}$ & Hypothesis \\
\hline
\end{tabular}

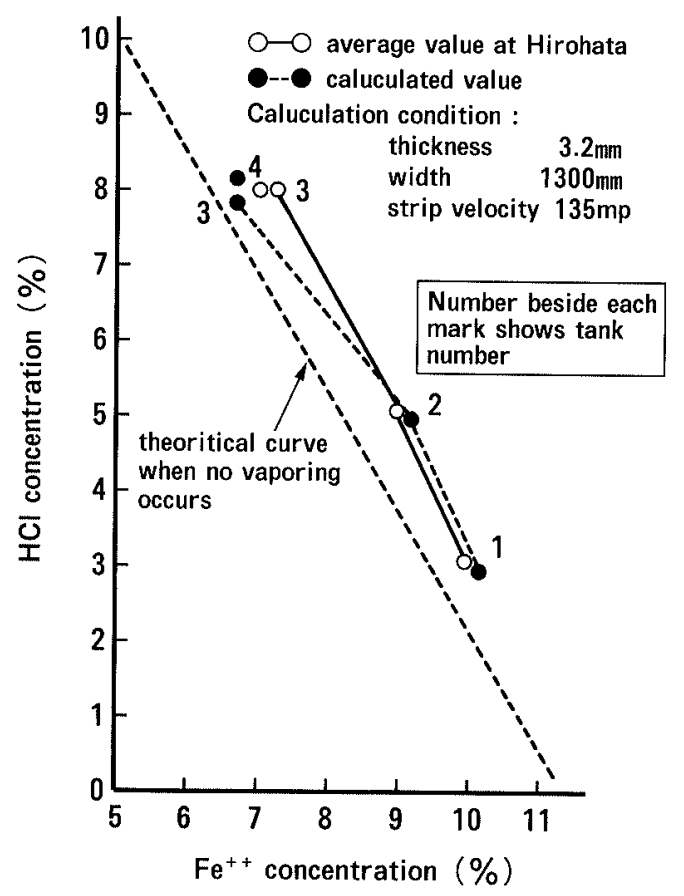

Fig. 26. Comparison between caluculated and actual value.

is taking mass balance of all the substance concerned tank by tank successively. All the premise taken into count is tabulated in Table $\mathbf{5}$.

The feature of the simulation is as follows.

(1) Descaling is not supposed to complete at the extreme end of the final tank. But finishing of descaling is allowed in certain zone of the final tank. This contributes greatly to add to precision of the simulation. Because it reflects actual operation more precisely.

(2) Descaling of strip edge and center is calculated separately.

(3) A lot of new findings are taken into count. Result of calculation is demonstrated in Fig. 26. Figure 26 shows that calculated values coincide well with actual values. The simulation is used in various ways. For example, it is used in determining the tank length required for given strip speed or in deciding the capacity of the $\mathrm{T} / \mathrm{L}$, and so on.

\section{Conclusion}

By studying various aspect of descaling of hot strip by $\mathrm{HCl}$ both experimentally and theoretically, methods of reducing the descaling time by half were established. Economically, however, the combination of $\mathrm{T} / \mathrm{L}$ which can elongate the strip by 3 to $5 \%$ and the Conventional dip pickling is the best choice.

\footnotetext{
Nomenclature

$k_{1}$ : Coefficient of descaling velocity at the first stage

$k_{2}$ : Coefficient of descaling velocity at the second stage

$n$ : Crack density at time $t\left(\mathrm{~mm}^{-1}\right)$

$n_{0}:$ Initial crack density $\left(\mathrm{mm}^{-1}\right)$

$n_{c}$ : Critical crack density at time $\tau\left(\mathrm{mm}^{-1}\right)$

$n_{f}$ : Final crack density $\left(\mathrm{mm}^{-1}\right)$

$N u$ : Nusselt number

Pr: Prandtl number

$R e$ : Reynolds number

$t:$ Time elapsed in descaling (sec)

$W:$ Amount of scale at time $t\left(\mathrm{~g} / \mathrm{m}^{2}\right)$

$W_{1}$ : Amount of scale which only reacts at the first stage at time $t\left(\mathrm{~g} / \mathrm{m}^{2}\right)$

$W_{0}$ : Initial amount of scale $\left(\mathrm{g} / \mathrm{m}^{2}\right)$

$W_{i 0}$ : Initial amount of $W_{0}$

$W \tau:$ Amount of scale at time $\tau\left(\mathrm{g} / \mathrm{m}^{2}\right)$

$\alpha=W_{i 0} / W_{0}$ : Constant determined by kind of scale

$\beta$ : Velocity of crack density growth $\left(\mathrm{sec}^{-1}\right)$

$\tau$ : Time at which crack density critical and the second stage of descaling starts (sec)

\section{REFERENCES}

1) M. Nagayama and S. Kawamura: Corros. Eng. (Jpn.), 13 (1964), 515.

2) K. Takagi: Tetsu-to-Hagané, 50 (1964), 637.

3) H. Hido and H. Naito: Bull. Jpn. Inst. Met., 16 (1997), 637.

4) N. Fukuda: Seitetsu Kenkyu, (1981), No. 304, 13803.

5) Kikaikogakubinran, ed. by JSME, (1977), 11-1.
} 